\title{
"On thin ice" - Discomfort using Sie among Danish students and teachers of German, and implications for Content and Language Integrated Learning (CLIL)
}

Maribel Blasco Copenhagen Business School

mbl.msc@cbs.dk

Bjarne Ørsnes

Copenhagen Business School bo.msc@cbs.dk

Keywords:

CLIL

pragmatic transfer

cultural cognitive dissonance

address forms

German

Denmark 
Abstract

The article discusses discomfort with using the polite/formal form of address Sie among students and teachers in German CLIL courses at university level in Denmark. Based on focus group interviews with students and teachers, we show that Danish students and teachers find it awkward to adopt the German Sie when German is the language of instruction in Denmark, typically resulting in pragmatic transfer of the Danish informal norm instead. Adopting a critical pedagogy perspective, we discuss how Sie seems to violate Danish cultural values of egalitarianism, causing cultural cognitive dissonance (CCD) in CLIL learning environments. We show that Danes cope with CCD by rejecting Sie or employing (sometimes quite complex) strategies to avoid direct address altogether. However, our investigation also reveals that CCD is partly locational/situational, and that Danes are less reluctant to use Sie in Germany or towards a native German teacher, suggesting a need to raise awareness about this issue in CLIL-courses and foreign language courses where language and intercultural training is taking place 'at home' and possibly with a teacher who is not a native speaker of the language. Finally, we offer some suggestions for attenuating this discomfort by rethinking the way that German polite forms of address are taught, and we make the critical point that a major premise of CLIL teaching - the idea of learning a foreign language 'on one's own territory may give rise to cultural resistance, to which teachers should be alert. 


\section{Introduction}

We are in Denmark, therefore it seems very awkward to have to say Sie to NN (i.e., the teacher) when other teachers do not require it. As already said: We are in Denmark at a Danish university. (Anonymous student evaluation, June 2013, our translation)

The above quotation comes from an anonymous evaluation of a $\mathrm{CLIL}^{1}$ (Content and Language Integrated Learning) course in which topics relating to contemporary German society and economy were taught in German by a Dane. Our curiosity was aroused by the students' seeming discomfort-and somewhat piqued attitude-toward being required to use the German polite/formal form for "you," Sie (henceforth V for Latin Vos) when in a Danish higher education context. The teacher had insisted on using $\mathrm{V}$ in these classes, following German conventions in higher education, ${ }^{2}$ as would seem appropriate in a CLIL class, and he was therefore surprised and discomfited by what he saw as the students' negative reaction to this choice. This episode motivated us to carry out research on this reported awkwardness or discomfort, which seemed to arise in particular when Danes spoke German to another Danea common occurrence in the CLIL classroom, where both the students and teacher are often Danish. We discovered that, in fact, it is not only Danish students (as in the quotation) but also their teachers who find it awkward to use $V$ in the CLIL classroom, and both groups find ways to avoid using it, despite knowing full well (teachers because they teach German, and students because they have been repeatedly taught this) that this is the conventional form of address in German higher education. In other words, they possess the necessary awareness and knowledge of appropriate German address forms, but seem unwilling or unable to mobilize this knowledge in certain situations. As Bardovi-Harlig and Dörnyei (1998, pp. 254-255) pointed out, "awareness is not likely to be a sufficient condition for the development of pragmatic competence," which has both a cognitive component (knowledge) and a sociocultural component (meaning in context) (Žegarac \& Pennington, 2000). V thus seems to be a marked choice for Danes in such situations even though it is the appropriate form in German. However, when in German-speaking countries, both teachers and students reported striving to use $V$, despite still experiencing some degree of discomfort. It seems, therefore, that both the level of discomfort Danes experience with $V$, and their willingness to use it, are affected by physical location (notably on "whose" cultural territory the FL is being spoken) and the cultural background of the interlocutor. ${ }^{3}$

We find this discomfort with $V$ striking, since it does not seem to arise when Danes are required to adopt other German language conventions, such as female forms of occupation names (die Kanzlerin vs. der Kanzler)-another distinction which is no longer in active use in Danish. It does not, therefore, appear to reflect a broader unease with, or rejection of, the German language or culture per se-only with this particular address form. The students' reported discomfort is problematic because learning the appropriate usage of specific foreign linguistic conventions-here, address forms which are an important aspect of register-is an integral part of mastering a foreign language and becoming interculturally and pragmatically competent (Bachman \& Palmer, 1996; Barron, 2006; Byram, 1997). Moreover, in today's increasingly culturally diverse societies, it is imperative that students are able to adapt to such foreign conventions, not only when abroad but also when using foreign languages "at

\footnotetext{
${ }^{1}$ CLIL is a teaching approach whereby content is taught in and through a foreign language (Pérez-Cañado, 2012, p. 315).

2 In Germany, the distinction between Sie and $d u$ is actively used, with Sie being the unmarked, formal form of address. As a gross generalization, $\mathrm{V}$ is used in formal situations, such as in higher education, business encounters, and media interviews, as well as in interactions with non-intimate adult interlocutors, e.g., strangers, neighbors and colleagues (see, e.g., Cook, 2014, and especially Besch, 1998, for other parameters affecting the choice of address form). In Denmark, this distinction has more or less been abandoned in favor of the Danish $T(d u)$ in all situations, with $\mathrm{V}$ being very marked and often associated with hierarchical (power) distance, e.g., in addressing royalty.

${ }^{3}$ Especially, the students claimed to be more willing to use $V$ with a native German.
} 
home," for instance in business environments where doing so is often expected. ${ }^{4}$ Research has shown that Danes' adaptation to German cultural norms in business interaction is considered somewhat inadequate by their German counterparts: Germans would prefer more formal and authoritative behavior on the part of their Danish colleagues (Vandermeeren, 2003, p. 25), and adherence to the Sie vs. Du norms in German is a part of this. Understanding what causes these difficulties in adopting foreign pragmatic conventions can pave the way for devising teaching strategies to overcome them.

We propose that Danes' reported discomfort with $\mathrm{V}$ has to do with "the very close relationship of pragmatic aspects of language behaviour to deeply held values and beliefs" (Yates, 2010, p. 300). In this case, $\mathrm{V}$ signals social distance, which is understood negatively in a Danish context, unlike in a German context. The informal $d u$ (henceforth $T$ for Latin $T u$ ), which is the default address form in Denmark, reflects the strong Danish cultural principle of equality, and this Danish cultural convention is transferred into students' and teachers' perceptions of $\mathrm{V}$ in the CLIL classroom, especially when the teacher is a native Dane, but also to some extent when the teacher is a native German. Students perceive $V$ as an address form that overtly signals deference, superfluous formality, or authority, and Danish CLIL teachers of German in Denmark perceive $V$ as creating a power distance between them and their students, which is at odds with their goal of maintaining an egalitarian classroom atmosphere and a less formal or more personal relationship with their students. ${ }^{5}$ So, for Danes interacting with other Danes or non-Danes in Denmark, even in a CLIL classroom, $V$ simply feels inappropriate or "wrong"-quite literally unless one is addressing royalty-and this meaning is transferred into their perceptions of $\mathrm{V}$.

Our study offers new insights into Danish native speakers' perceptions of the formal German address form (V) and seeks to explain the discomfort the form reportedly causes them, especially when in a Danish context. We investigated the following question: How do Danish students and their teachers perceive the use of the German $V$ in the classroom, and why do they report being more willing to, and comfortable with, using $V$ in some situations and with some interlocutors but not others? We took our overall theoretical point of departure in language attitudes and intercultural pragmatics, with a particular focus on the influence of cultural context, which we regarded as influencing the CLIL educational context in this case (Gardner, 2007). We combined this with Maertz, Hassan, and Magnusson's (2009) concept of cultural cognitive dissonance to explain the discomfort reported by students in situations requiring deviation from deeply ingrained Danish cultural norms that shun overt acknowledgement of status differences, as would be required by the use of $\mathrm{V}$. In line with the aim to investigate speaker perceptions, our study drew on primary data gathered from student evaluations, and from student and teacher interviews, about their perceptions of $\mathrm{V}$, supplemented by informal observational data (which prompted our study) pertaining to students' actual usage of $\mathrm{V}$ gathered from German CLIL teachers' classroom and examination experiences. As Kinginger and Belz (2005, p. 377) noted, verbal reports on address form choice are a valuable source for understanding the development of pragmatic knowledge. At the outset, our main focus was on the students, but our data revealed that Danish teachers' perception of $\mathrm{V}$ in fact reflects that of their students: i.e., $\mathrm{V}$ is felt to be "wrong" in a Danish context but appropriate in a German context. Moreover, teachers reported quite different approaches to $\mathrm{V}$, ranging from strict insistence on using $\mathrm{V}$ to avoiding it completely. We therefore suggest that students' reported discomfort with $V$ may be exacerbated by $a$ tendency to teach address forms inconsistently and/or in a rigid fashion that overemphasizes the dire social consequences that can result from failure to use $\mathrm{V}$ appropriately and does not reflect the variation and negotiation that characterize contemporary real-life usage (Clyne,

\footnotetext{
${ }^{4}$ See article in the Danish business newspaper, Børsen, which states the need for Danes to master German pragmatic conventions (Børsen, March 6, 2015).

5 See also article from the Danish newspaper, Information (July 29, 2014), on the modern teacher, who is supposed to be an authority without being authoritarian.
} 
Kretzenbacher, Norrby, \& Schüpbach, 2006, p. 296). We also offer some recommendations for how CLIL teachers might tackle these issues.

In line with our focus on how cultural context may influence Danish students' perceptions of $\mathrm{V}$, we located our study more broadly within a critical pedagogy (CP) approach that emphasizes the linkages between what goes on in classrooms and wider sociocultural tendencies and ideologies and is attentive to the role of education either in reproducing or challenging dominant ideologies outside the classroom (Giroux, 2001). Classrooms are therefore never just "neutral" terrains through which knowledge can be seamlessly transmitted (Hornberger \& Link, 2012); rather, they are regarded as microcosms of the society in which they are located (Breen \& Littlejohn, 2000, p. 20) as well as sites for the construction and negotiation of learners' cultural norms, beliefs and identity, and power and hierarchies (Giroux, 2001), all of which have been found to potentially affect how students interact in a second language, among other issues (Dalton-Puffer, 2007, p. 40; GardnerChloros, 2009). From this perspective, classroom challenges in teaching language and intercultural competences are particularly salient at a time when skepticism toward foreignness on one's "own soil" has intensified as a result of the recent influx of refugees and other migrants to Denmark and elsewhere. Although reports of overt racism are rare in Denmark, tendencies toward strong attachments to Danish culture when at home have been noted (Haas, 2008). From a critical pedagogy perspective, alertness to such attachments in classrooms is therefore an important step in training intercultural sensitivity in a context where the Danish population is growing more culturally diverse, and it is therefore important that foreign language teachers are aware of this issue (Liao, 1996).

Although still explorative in nature, our study offers new insights into the discomfort associated with foreign language acquisition, with implications notably for German CLIL in a Danish educational context and pragmatic competence learning. The article begins with theoretical reflections on attitudes toward language features, such as forms of address, and the possible speaker responses which these can occasion. This is followed by a description of the methodology, the presentation of the data, and a discussion placing the empirical findings in a broader societal frame. Finally, we present our conclusions and raise questions for future research.

\section{Adaptation to foreign pragmatic norms: Theoretical perspectives}

In order to understand why students report discomfort when required to use $V$, we first take a closer look at factors that influence people's adaptation to particular linguistic features in foreign languages. The benefits of such adaptation-and the pitfalls of failing to adapt-are well documented in research on both sociolinguistics and intercultural communication, much of which is explicitly aimed at facilitating such an adaptation by improving knowledge and awareness of other languages and cultures ( $\mathrm{Ng}$, Van Dyne, \& Ang, 2012; Thomas et al., 2008; Trosborg, 2010). Yet, studies of language attitudes and intercultural pragmatics have shown that knowledge of these benefits, and of the rules governing appropriate linguistic choices in a foreign language, are not always sufficient-various individual and contextual factors can intervene to affect how learners interpret foreign pragmatic conventions and whether they adopt them (Barron, 2006; Gardner, 2007; Ishihara \& Cohen, 2014; Jeon \& Kaya, 2006; Liddicoat, 2006; Spencer-Oatey, 2010).

Gardner (2007) emphasized that foreign language learning is different from studying other subjects insofar as it involves adopting elements of another culture; moreover, individuals' motivation to learn a foreign language is influenced by their own cultural and educational contexts. Regarding cultural context, Gardner identified a dimension called integrativeness, defined as "openness, or openness to cultural identification" (2007, p. 15). Learners' culture, he claimed, influences their "attitudes, beliefs, personality characteristics, ideals, expectations" (2007, p. 13) and general motivation when it comes to foreign language learning. Regarding the educational context, he identified a dimension termed "attitudes 
toward the learning situation," which encompasses features of both the broader educational system and the immediate classroom experience, including "the expectations of the system, the quality of the program, the interest, enthusiasm, and skills of the teacher, the adequacy of the materials, the curriculum, the class atmosphere, etc." (2007, p. 14). These two contexts can also influence each another, and both influence motivation and thereby achievement (Gardner, 2007). A similar idea may be found in socio-cognitive approaches to pragmatics, which consider both the context constituted by an individual's "background and biases" located in his or her mind, and, at the same time, the real-world situation (such as a classroom embedded in a particular national context) in which he or she is located in exploring the "third space" of meaning that results from "the interplay of prior experience and current, actual, situational experience, which are both socio-cultural in nature" (Kecskes, 2014, p. 129). This can also work the other way around, with research showing that language use in the classroom can constitute a linguistic and cultural resource that is not only academic but may also be used to construct and negotiate meanings, group or individual identities, relationships, and power dynamics with other classroom actors and which has implications for their empowerment or disempowerment (Auerbach, 1995; Fasold, 1984). In this regard, Hinkel (2014, p. 398) noted that "in the classroom, the roles of the student and the teacher are defined by the sociocultural values of the larger community and the society."

Speakers may also transfer their own native language perceptions of what constitutes appropriate performance in a given situation to the second language (Olshtain \& Cohen, 1989), a phenomenon known as pragmatic transfer, i.e., "the transfer of pragmatic knowledge in situations of intercultural communication" (Žegarac \& Pennington, 2000, p. 165). Socio-pragmatic failure, where the speaker violates a cooperative or politeness principle, may often result (Luo \& Gao, 2011). Various factors have been found to influence pragmatic transfer, such as linguistic and communicative proficiency, awareness of the correct usage situation, and other input conditions (e.g., Schmidt, 1993, 2001; Sharwood-Smith, 1991), as well as the effects of speech acts (see, e.g., Swain, 1995 on the "output" hypothesis) and normative beliefs about what constitutes a culturally appropriate utterance in a given situation (Hinkel, 2014; Wierzbicka, 2010). Regarding the latter, Wierzbicka's research on cultural scripts, defined as the "tacit norms, values and practices widely shared, and widely known (on an intuitive level) in a given society," (Wierzbicka, 2010, p. 43) has shown how languages have "key words" and expressions with particular emic meanings-as in the case of the formal "you" in Danish compared to German-that are associated with particular speech practices, which can lead to pragmatic transfer and miscommunication between speakers (Wierzbicka 2010, p. 47).

Indeed, politeness conventions, such as address forms, assessments of interlocutors' social distance and social power, rights and obligations, and the degree of imposition involved in different linguistic acts, vary considerably cross-culturally (Ishihara \& Cohen, 2014; Kasper, 1992 , p. 209). Some research has found that despite being perfectly aware of the correct form, learners nonetheless tend to transfer their L1 politeness conventions to the L2 (see, e.g., Hinkel, 2014), and that accessing learned L2 forms in order to perform them can require a great deal of attention and mental energy (see Norouzian \& Eslami's 2016 review). Such conventions can also evoke strong emotional responses in intercultural situations (Culpeper, Schauer, Marti, Mei, \& Nevala, 2014), and pragmatic transfer may also be carried out "on purpose" because the learner does not want to adopt the foreign behavior (Kecskes, 2014, p. $63 \mathrm{ff}$.). As Yates (2010, p. 301) pointed out, due to early socialization, non-native speakers may not feel comfortable with the pragmatic norms of another linguaculture and may consequently decide not to follow them, even if they are aware of them.

Barron's (2006) review of learners' acquisition of German address forms in a study-abroad context noted that existing studies have shown that learners generally tend to avoid formal address forms, not only in German but also in other languages. She also noted that the acquisition of declarative knowledge about the use of address forms may be more complex 
than assumed. Faerch and Kasper (1989) suggested two reasons for why Danes have difficulties distinguishing formal and informal pronouns of address: first, the morphological complexity of personal pronouns in German; and second, the fact that $\mathrm{V}$ is simply less used in Danish. However, neither of these studies investigated students' or teachers' perceptions of $\mathrm{V}$ in explaining students' difficulties with using Sie in German, or other factors mediating these attitudes, beyond knowledge/awareness and mastery of the complex rules of usage. Even fewer studies have focused specifically on how culture might influence students' perceptions of particular language elements in CLIL classrooms ${ }^{6}$ (Coyle, 2007; Pérez-Cañado, 2012); and to our knowledge, no research exists on these topics specifically in a Danish context, with the exception of Ørsnes (2016), who presented a case in which Danish students overtly resisted adopting the German polite form of address in the CLIL classroom. He hypothesized that this resistance was due to cultural cognitive dissonance (Maertz et al., 2009), which arose because $V$ violated ingrained values, notably egalitarianism, associated with contemporary Danish society (we return to this point below). However, his study did not follow up on this hypothesis by, e.g., investigating how Danish students and/or teachers perceive $\mathrm{V}$ in the CLIL classroom or whether other factors may modify their perceptions.

In seeking to theorize the discomfort reported by students and teachers when using $\mathrm{V}$ in a CLIL classroom in Denmark, we applied Maertz et al.'s (2009, p. 69) conception of cultural cognitive dissonance (CCD), defined as "anticipating or currently perceiving inconsistencies between one's behaviors, executed or condoned in order to conform to the host culture situation, and one's VABNs [values, attitudes, beliefs, and norms]." The psychological challenges that can result from having to adopt behaviors that are at odds with one's VABNs may produce emotional responses such as distress, embarrassment, insecurity, guilt, or anxiety, as well as other forms of stress (Maertz et al., 2009), which can in turn interfere with learners' willingness or ability to produce a required cultural behavior-even if they rationally understand the benefits of doing so (Molinsky, 2007). Since changing the normal language of the classroom places heavy demands on both teachers and learners (Mehisto, 2008, p. 94) and alters the L1-based norms governing the teacher-student relationship, since both must communicate in the L2, CCD is not unlikely in a CLIL context and may consequently erode the students' willingness to engage in learning (Dewaele, 2011, p. 24).

CCD can trigger coping responses designed to reduce any dissonance experienced by learners with a view toward protecting their self-image and sense of competence and morality. Maertz et al. (2009, p. 69) identified six CCD coping strategies that may be deployed either singly or in combination: (1) VABN modification: modifying one's own values, attitudes, beliefs, or norms to adapt to the new situation; (2) perceptual modification: changing one's view of the meaning of a situation; (3) self-affirmation: offsetting negative feelings caused by a threat to one's VABNs by steadfastly reaffirming one's own identity; (4) rationalization: seeking excuses or acceptable explanations for the inconsistency; (5) confession-redemption: confessing to having succumbed to the inconsistency and promising not to repeat it; and/or (6) host $V A B N$ rejection: outright resistance or even flat refusal to perform or condone the behavior causing the inconsistency. We note here that although it is usually teachers who are assumed to have the greatest power and authority in the classroom, "students retain an absolute veto over activities the teacher tries to impose" (Lemke, 1990, p. 71) in the sense that they can, in principle, refuse or be otherwise unable to comply with teacher instructions, e.g., for the above-mentioned reasons. We will return to this point in the discussion.

First, we describe our methodology, followed by a presentation of our data about perceptions of German V among Danish students and teachers.

\footnotetext{
${ }^{6}$ Indeed, little research exists on CLIL at the tertiary level (Pérez-Cañado, 2012).
} 


\section{Methodology}

This study was triggered by our curiosity about the failure observed among students in using the $\mathrm{V}$ form in CLIL in German classes and even in oral examinations in Denmark, where one of the authors was a teacher/examiner, as well as with negative comments about classroom use of V in course evaluations (Ørsnes, 2016). We compared these with reports ${ }^{7}$ written by Danish students while on exchange in Germany, which showed that although they still found it awkward to use the $V$ form, they nonetheless did their best to comply when in Germany. To further probe this discrepancy between the students' use of $V$ "at home" and in Germany, we conducted a review of literature on language attitudes and intercultural pragmatics in connection with foreign language learning, including CLIL. This revealed little research on attitudes toward particular linguistic forms at home vs. abroad, so we formulated the exploratory research question outlined earlier and conducted interviews with Danish students as well as with German and Danish teachers of German in Denmark to determine whether they also had difficulties using V, either themselves or with their students. Specifically, we conducted (1) loosely structured interviews with Danish and German teachers of German at two Danish universities (including our own); and (2) a focus group interview with Danish students from first-, second-, and third-year Bachelor's German CLIL classes at our university. In both cases, we explored the interviewees' perceptions of $\mathrm{V}$ in general and in different situations, such as in the CLIL classroom vs. authentic interaction in German-speaking countries, as well as any strategies they used to cope with their own or their students' reactions to using $\mathrm{V}$. Six teachers and seven students participated in the interviews. In the remainder of this article, we primarily refer to these interview data. ${ }^{8}$ In analyzing the interviews, we were guided by the following themes derived from the literature and from our own initial observations:

- Any relationship between use of $V$ and context: Concretely, under which circumstances do students/teachers report/claim to use $\mathrm{V} ;$ and in which situations do teachers require that students use $\mathrm{V}$ ?

- The meaning of $V$ : What meanings and values do students and teachers associate with the use of $\mathrm{V}$ in different contexts?

- Students' and teachers' feelings about $V$ in different contexts: We paid particular attention to classic emotional expressions of CCD, i.e., distress, embarrassment, insecurity, guilt, or anxiety, as described in the literature on CCD.

- Students' and teachers' practices regarding $V$ and $T$ : i.e., Whether they use $V$ and, if so, in which situations? We paid particular attention to the six CCD coping strategies outlined in Maertz et al. (2009, see earlier).

Because our research was partly carried out in a context in which both authors are involved, special attention was paid to the ethical issues that can arise when working within one's own professional community (Fouché \& Chubb, 2016). We therefore observed the Danish Code For Research Integrity ${ }^{9}$ and were guided by the five ethical principles outlined in Hammersley and Traianou (2012): (i) minimizing harm, (ii) respecting autonomy, (iii) protecting privacy, (iv) offering reciprocity, and ( $v$ ) treating people equitably. We did not consider (i) and (v) relevant since our research topic was not potentially sensitive or harmful toward our informants. We addressed autonomy by providing informants with detailed information about the purpose and uses of the research and by ensuring voluntary participation; privacy was

\footnotetext{
7 These reports were gathered by one of the authors in connection with a course on cultural analysis, which had run for several years and drew on students' reports of their exchange experiences at foreign universities.

8 The data are in Danish, German, or English. All Danish and German quotes were translated into English by the authors.

9 http://ufm.dk/en/publications/2014/the-danish-code-of-conduct-for-research-integrity
} 
addressed by anonymizing participants and study program affiliations. Interviewees were recruited from all three years of a BA program with a specialization in German via email invitation. Reciprocity involved giving all interviewees access to our data and results as well as offering them refreshments and an edible gift.

\section{Limitations of the study}

The study had several limitations. First, we could not infer whether our findings about $\mathrm{V}$ are generalizable to situations outside the university classroom, e.g., work or private contexts, although our interview informants do report on difficulties using appropriate address forms in both private and work contexts. Second, we recognize, as do other scholars (Haugh, 2010; Wierzbicka, 2010), the dangers of essentialism and stereotyping associated with using nationality as our primary unit of analysis to explain why $V$ is endowed with negative connotations in a Danish context. There may be other pertinent categories at play, such as individual personality, regional attachment, social class, gender, educational level, or discipline, that might affect Danes' perceptions of V. Still, we consider national culture relevant since national cultural norms can, if breached, occasion misunderstandings (Wierzbicka, 2010).

Indeed, the literature on Danish culture almost unanimously emphasizes equality and low power distance as dearly held cultural values in contemporary Danish society, values which are also manifest in basic pedagogical principles in the school system (Hervik, 2004; Jenkins, 2011; Jensen, 2006; Kingsley, 2012; Knudsen, 2002; Nørmark, 2013). Since V was generally viewed by the interviewees as jeopardizing an "equal footing," it was impossible to avoid exploring its connection to the attachment to values associated with Danish national culture in the literature. In that regard, the literature emphasizes the role of power or hierarchical relations in the development and use of different forms of address, starting with the classical account of $\mathrm{V}$ and $\mathrm{T}$ in Brown and Gilman (1960), who mobilized the concepts of power distance and solidarity (social distance) as being denoted by address forms, inter alia. Note, however, that we deliberately speak of egalitarianism as a cultural value and not as a feature of Danish society. In other words, it is an integral part of Danish self-conception, one which shuns overt manifestations of hierarchy. We do not mean to imply that contemporary Danish society is consistently egalitarian or that hierarchical relationships or other manifestations of power distance do not exist in Denmark. Future research should explore other categories determining perceptions of foreign pragmatic norms and broaden the focus to include nonacademic settings.

A further limitation was that we relied on interview data in which students reported on their own perceptions and use of address forms (Garrett, 2010, p. 37 ff.). Since values are internalized (Rokeach, 2008) and people are not necessarily aware of them, we could not expect the interviewees to be able to explain what caused their reported discomfort when using $V$ in German in a Danish setting or whether they even used V. We could only establish that $\mathrm{V}$ was associated with negative connotations by both students and teachers. Finally, we only carried out a small number of interviews with teachers and students who volunteered to participate, since recruitment was very challenging, especially recruiting students. With these limitations in mind, we proceed to the presentation of the data.

\section{Data presentation}

Our data were organized around the following three topics: (1) perception of classroom practices with regard to the use of foreign pragmatic conventions; (2) perceptions of $\mathrm{V}$ in German; and (3) strategies to cope with V. We discuss students and teachers separately, contrasting the students' responses with the teachers' observations. Table 1 and Table 2 give information about the individual participants in the interviews. All students were Danish and were attending Copenhagen Business School (CBS). At CBS, they were taught German by 
Danish teachers only; additionally, these teachers employed different practices regarding the use of $\mathrm{V}$ in class.

Table 1: The students in the focus group interview

\begin{tabular}{|l|l|l|l|l|l|l|}
\hline $\begin{array}{l}\text { Student } \\
\text { A }\end{array}$ & $\begin{array}{l}\text { Student } \\
\text { B }\end{array}$ & $\begin{array}{l}\text { Student } \\
\text { C }\end{array}$ & $\begin{array}{l}\text { Student } \\
\text { D }\end{array}$ & $\begin{array}{l}\text { Student } \\
\text { E }\end{array}$ & $\begin{array}{l}\text { Student } \\
\text { F }\end{array}$ & $\begin{array}{l}\text { Student } \\
\text { G }\end{array}$ \\
\hline $\begin{array}{l}\text { Female } \\
\text { 3. year }\end{array}$ & $\begin{array}{l}\text { Female } \\
\text { 3. year }\end{array}$ & $\begin{array}{l}\text { Female } \\
\text { 2. year }\end{array}$ & $\begin{array}{l}\text { Female } \\
\text { 2. year }\end{array}$ & $\begin{array}{l}\text { Female } \\
\text { 1. year }\end{array}$ & $\begin{array}{l}\text { Female } \\
\text { 2. year }\end{array}$ & Male \\
3. year \\
\hline
\end{tabular}

Table 2: The teachers in the loosely structured interviews

\begin{tabular}{|c|c|c|c|c|c|}
\hline $\begin{array}{l}\text { Teacher } \\
\text { A }\end{array}$ & $\begin{array}{l}\text { Teacher } \\
\text { B }\end{array}$ & $\begin{array}{l}\text { Teacher } \\
\text { C }\end{array}$ & $\begin{array}{l}\text { Teacher } \\
\text { D }\end{array}$ & $\begin{array}{l}\text { Teacher } \\
\mathrm{E}\end{array}$ & $\begin{array}{l}\text { Teacher } \\
\text { F }\end{array}$ \\
\hline Female & Female & Male & Female & Male & Female \\
\hline German & German & German & German & Danish & Danish \\
\hline CBS & UCPH & UCPH & UCPH & CBS & CBS \\
\hline
\end{tabular}

\section{Use of $\mathrm{V}$ in the classroom: Talking about practices}

\section{Students' classroom practices regarding V}

Most student interviewees claimed that it was reasonable to use $\mathrm{V}$ in class when German was the language of instruction, also when the teacher was a native Dane, even while acknowledging the difficulty with using $\mathrm{V}$ in a Danish context:

Maybe you should simply decide to do it consistently-use Sie and that is the way it is. It prepares us students to be well equipped for mastering these situations when we get there $(. .$.$) (Student B)$

At the beginning I thought a lot about it and I think it has been good because it makes the teaching more serious and you get prepared to interact with Germans in general (Student F)

However, the students emphasized that teachers should make it very clear why they had to use $V$ and remind them of this throughout the course. This request for justificatory metacommunication suggests that requiring $\mathrm{V}$ is not completely acceptable to them:

Maybe you simply have to make it clear that we do this for the sake of the students (Student B)

As long as you really emphasize that it is part of the objective of the course and we do this for the benefit of the students (...) and maybe several times during the course (Student A)

You must tell exactly why this is so (Student F)

Despite acknowledging the importance of learning how to use $V$, many of the students admitted that they tended to use $T$ in class, citing their personal relationship with teachers, "naturalness," and the Danish context as reasons: 
But in class here, I don't (i.e., use Sie). I think it is very seldom (...) I think we have a more personal relationship to our teachers maybe because we are not so many (Student C)

I think I use $d u$ in class (...) and then it is natural for me to use $d u$ in class, also because we are in a Danish context [italics by authors]. Maybe that is wrong, when it is in a Danish context (Student D)

Another student remarked that she tended to use $T$ out of habit even when making a class presentation to a fictitious German audience:

It is a habit (i.e., for me to use $d u$ ). It is a matter of getting accustomed (...) You are in a flow and you just don't think about it (Student A)

The students also admitted that uncertainty about the use of $\mathrm{V}$ and $\mathrm{T}$ made them nervous about speaking in German in professional contexts:

We had a guest teacher at some point [a guest teacher from Hungary, speaking German]. I remember that we were all very quiet, hardly anyone said anything to her, because we were far too nervous to address her incorrectly or speak to her in the wrong way about the topics (Student $\mathrm{C}$ )

All the students agreed that it made a huge difference whether or not the teacher was a native speaker of German; using $V$ was much easier for them in the latter case:

People know that a German has grown up with this form of address and therefore it is easier to accept (...) (Student A)

They also speculated that it must be easier to accept $\mathrm{V}$ if one has been exposed to it in a genuine German context:

I am sure that some of those who have not been in Germany find it very odd. I think some find it very odd, especially those who do not speak very good German (...) But those who have worked in Germany find it quite natural (Student E)

In fact, the students claimed that they used $\mathrm{V}$ when needed if they were in German-speaking countries, even to the point of overusing it inappropriately, as this quote shows:

I have lived in Berlin and worked in a restaurant (...) we were told always to use Sie. I had a different experience though. I just used Sie as I would say "hello." I used it once toward a young guy who came with his friends and he made fun of it. He was not insulted but I realized that it is not always a good thing to do, it is not only politeness. He thought I was making a joke. (...) This was the only mistake I have made using Sie. I don't think of it. I know that it can be a problem (Student D)

\section{Observations by teachers about students' use of $\mathbf{V}$}

Despite the students' reported positive attitude to the use of $\mathrm{V}$ in class, the teachers could not corroborate that the students actually used V in class. In line with the students' accounts, presented above, some Danish teachers observed that most students continued to use $T$ even in tasks where $\mathrm{V}$ had been presented as the preferred address form. In the presence of a native German teacher, however, the teachers reported that students exhibited a range of different practices toward V:

I only use Sie in class and the students paying attention also use Sie when addressing me (Teacher B) 
Another native German teacher noted that some Danish students experimented with $V$ even though he himself used $\mathrm{T}$ in class.

Sometimes I experience (...) that students on their own initiative start to say Sie to me, and sometimes these are people who do not necessarily have a German background but they want to rehearse. Because they have heard that you are supposed to say Sie to teachers (Teacher C)

Avoidance of $\mathrm{V}$ was, however, regularly observed by teachers at oral exams involving role plays between a Danish teacher and a student, where the student was supposed to simulate an authentic verbal exchange with a German. Native Danish students tended to use $T$ despite having explicitly planned to use $V$ in the position papers they prepared for the oral exam. At the actual exam, however, they still avoided $\mathrm{V}$, even though the teachers formally considered this an error:

In an oral interaction it is definitely a mistake (i.e., not to use Sie)-typically two strangers get together and if they (i.e., the students) use $d u$, and they usually dothen it is a mistake because you run the risk of insulting people (Teacher $F$ )

It also seemed that the Danish students had difficulties with $V$ even in professional contexts in Germany:

And then I had a very telling situation when I worked 2 years at the embassy in Berlin, they had many internships, Danes on internships, and they had huge difficulties in speaking up in official contexts because they were insecure whether a $d u$ or a Sie slipped from their mouth (...) If you master these rules you are more secure when speaking German, you are not paralyzed at the thought of saying something wrong (Teacher A)

I noticed with the students on internships that they were insecure and were more silent than otherwise at meetings and it came from insecurity with respect to the forms of address (Teacher $\mathrm{A}$ )

Otherwise, the teachers observed that exposure to German conventions in a German context positively influenced students' use of $V$. Students returning from internships and study stays in Germany were much more inclined to use $V$ upon their return (at the beginning, at least), and they reflected more on the use of $\mathrm{V}$ and $\mathrm{T}$. The teachers also noted that the students used V on trips to Germany.

(...) and also I experience that students who were on Erasmus [a student exchange program] after returning started to say Sie to me, which they had not done before and sometimes they kept doing so or they returned to $d u$ after a while (Teacher $D$ )

Yes, exactly, in the shops (i.e., on a trip to Germany) they used Sie, that came natural to them (...) they had deliberately engaged in this situation (Teacher B)

\section{Teachers' classroom practices regarding $\mathbf{V}$}

The native Danish teachers reported being very reluctant to use $\mathrm{V}$ in class as well (with the exception of one of the authors, who insisted on doing so). Both native Danish teachers in the focus group used $T$ in class, arguing that $T$ is the convention at Danish institutions and is consistent with the Danish teaching style, which embraces a close and/or relaxed relationship between teacher and students and an atmosphere of equals and critical dialogue, as the following quotes show: 
I sense this distance and I have the feeling that the students do so too. When we get into situations with more emotional subjects or disagree on something they relapse into du immediately (Teacher F)

I know them very well, and that is the clue. I have extremely big difficulties in addressing them with Sie (Teacher E)

$V$ is only used occasionally when explicitly part of a task or group work, but even here the Danish teachers tended to relapse to $\mathrm{T}$ :

The students did not have difficulties in using first name and Sie (...) But it did not really work since I relapsed into $d u$ constantly during their presentations. (...) It got messed up because I wasn't really prepared myself (Teacher E)

They also had difficulties using $\mathrm{V}$ when native German students addressed them with $\mathrm{V}$ in class or at oral exams:

Even yesterday I had this awkward situation with a student whom I hardly knew from class. (...) I addressed him with $d u$ and he used Sie because he is German. And so did the external evaluator when she spoke German. Finally I switched to Sie, which is very awkward in itself (Teacher F)

At the same time, the Danish teachers had no difficulties using V in Germany:

I never make a mistake using Sie in Germany, well hardly ever (...) and it seems quite natural to me (Teacher F)

\section{Perceptions of German V}

\section{Students}

In many of the students' statements, $\mathrm{V}$ was directly or indirectly associated with negative feelings or with hierarchical attitudes:

It does not necessarily mean that you are in a bad mood (Student A)

Or that you are not prepared to help (Student C)

I would use Sie in class (i.e., as a teacher of German). The students would get to know me and during the break, they would find out that I am not that hierarchical (Student D)

In general, the students found that using $\mathrm{V}$ made for a more serious and committed learning environment. Although the students claimed that they found this to be positive, they also clearly associated it with a more distanced and/or professional teaching approach:

In some ways there is more distance in the class, but it is a positive distance, I mean that we take things more seriously (Student B)

There is no doubt about that (i.e., that it changes the atmosphere) When I think of the use of Sie in class, I think, now it is serious business, you really have to perform, it is more serious (Student $\mathrm{G}$ )

In the German program we are so few and you may have the same teacher through 6 years (...) So I think it is really important to keep this professional distance to each other (Student B) 
Other students did not find that $V$ influenced the learning environment, but they acknowledged that $\mathrm{V}$ could be perceived as introducing a power hierarchy, something that (once again) requires a justification by the teacher:

So I don't think it influences the teaching environment (...) It can be seen as a way of demonstrating power. It must be made clear that we do this for rehearsal (Student D)

The following quote is not part of our dataset, but it illustrates the association of $V$ with power distance very clearly. A Danish exchange student in Germany commented on his experiences in an interview with the German newspaper, Die Zeit Online:

In Mainz I study International Economics and Public Policy. My courses are in English, but the language courses are in German of course. There I have to address the professors as Sie. I find that odd, because it means you distance yourself from the interlocutor. In Denmark we always use $d u$. This means that we are on the same level from the very beginning, also with the teachers (Interview with Danish student in Germany, Zeit Online, August 2, 2015, our translation)

This student referred to teachers and students as being on the same level in Denmark, showing how $T$ is associated with equality and $V$ with hierarchical distance (i.e., a negative interpretation of the social distance created by $V$ ). The quote from an anonymous evaluation given in the introduction also shows how $\mathrm{V}$ is interpreted as a way of paying respect to the teacher. Likewise, in our interviews, the students also kept returning to $\mathrm{V}$ as a manifestation of inequality:

I think it touches upon the Law of Jante ${ }^{10}$ of people (...) I could imagine that people see it as if they had to say Sie to a Danish teacher, you feel superior to them and people are insulted even though there is no real reason, I think (Student $A$ )

He feels superior to us (Student A)

\section{Teachers}

The teachers, however, associated $V$ with social distance but not necessarily with the additional implication of hierarchical or power distance. This interpretation of $\mathrm{V}$ is consistent with most analyses of the contemporary system of German forms of address (e.g., Cook, 2014).

I see it very clearly with people I know in Berlin and to whom I want to keep a certain distance. I demonstratively stick to the Sie-form and their family name, in my neighborhood for instance. (...) And it is plain politeness in a German context (Teacher E)

One day he (i.e., a senior German teacher) took his beer and introduced himself with his first name, and so did I, and after that we had completely different conversations also discussing political issues (Teacher E)

Social distance seems not to be regarded positively in a Danish context. One of the native Danish teachers even experienced a self-identity challenge when using V:

\footnotetext{
10 The Law of Jante is a particular group behavior which criticizes accentuation of individual success and achievement. It is considered to be dominant in Scandinavian countries (Den Store Danske Encyklopædi, 1997).
} 
I use $d u$ toward the students because I think I feel a certain distance to myself when I am speaking German as to who I am myself-and using Sie I have the feeling of transferring certain different norms (Teacher $F$ )

The native Danish teachers associated the respective use of $\mathrm{V}$ and $\mathrm{T}$ with different learning contexts. $\mathrm{V}$ may be appropriate in the (purportedly) more authoritarian and professional German teaching context:

I tend to think that professional is the clue word, also in teaching. I think-in my opinion -teaching in a German context is more professional in the sense that the teacher is telling what is the right thing to do. I want to get away from that. (...) I don't have the answers to everything, we have to do this together and you are going to learn something. (...) If I were to give a presentation to students that I don't know-also in a Danish context-I would immediately use Sie (Teacher F)

In a Danish learning context, however, $\mathrm{V}$ is considered detrimental. Teaching is supposed to take place in a supportive atmosphere where students and the teacher work closely together to enhance learning. The teachers gave the following reasons for using $T$ :

I want to consider my students as friends (Teacher E)

(...) and I am very much in favor of a teaching based on dialogue and that the students should take over responsibility themselves and that I am the capacity on the topic but I want them to be able to say whatever they want and to enter into a critical dialogue (...) if we sense this distance due to the language we could at least reduce distance through the $d u$-form (Teacher F)

I think we have this Danish egalitarian idea of teaching that we are creating a common space and common learning (Teacher F)

T supports this goal by representing the Danish teachers' egalitarian values, whereas $V$ does not, as it is associated with (social) distance. The native German teachers agreed that $T$ diminishes the distance between interlocutors and that it denotes an egalitarian value, although that does not mean that Danes are all equal in practice:

I am not sure it has something to do with the language, it has rather something to do with political-cultural conditions, because it usually carries this idea of egalitarianism (...) (Teacher C)

(...) $d u$ has no social connotations. When you say $d u$ it does not mean that we are equal. Nobody thinks so. It is a kind of uncomplicated interaction (Teacher $\mathrm{C}$ )

The native German teachers also found that $\mathrm{V}$ can be detrimental to the teaching context. Speaking a foreign language puts the students in a stressful, alienating situation rather than in a learning environment that, according to them, should provide a safe environment:

Seriously, I think that it is a stressful situation for some of them to speak the other language and exactly this (i.e., using Sie) is what they leave out while they are concentrating on grammar. That would be my interpretation (Teacher A)

The emotional setting is very important in the teaching context. And when using Sie means that the students feel rejected you will also have problems teaching them to use it (Teacher B) 


\section{Strategies to cope with $\mathbf{V}$ in German}

The data suggest that $\mathrm{V}$ causes Danes to experience cultural cognitive dissonance and, following Maertz et al. (2009), we would therefore expect them to employ strategies to cope with this. Notably, Maertz et al. (2009) identified rejection of the foreign cultural norm as a coping strategy. Yet when asked about this, the students claimed they did not use any coping strategies. The following data were therefore primarily based on teacher observations reported at our interviews. The teachers described how Danish students avoided $\mathrm{V}$ by using $\mathrm{T}$, even in high-stakes situations, such as exams. This avoidance does not appear to be deliberate, however. When we presented the students in our interviews with their teachers' reports about their avoidance of $\mathrm{V}$, the students explained it as a kind of "slip of the tongue": "You are in a flow and do not think about it" (Student A). Pragmatic transfer seemed unintentional. However, we also observed a refinement of the rejection strategy discussed in Maertz et al. (2009). Two native German lecturers observed that if the students were forced to use $V$, some of them would use strategies to avoid direct address-and interestingly, one of the lecturers even admitted to lapsing into $d u$ at times:

Sometimes we pretend we are in Germany and we try to simulate situations from a German university. Then I usually address the students with Sie, sometimes I relapse into $d u$, I also forget myself. In answering it is usually so that they do not have to address me. They make a passive attempt or information is simply presented and discussed. They avoid the direct address. Perhaps it is deliberate or the situation does not encourage them to use Sie (Teacher D)

I can confirm that many try to avoid it (i.e., use Sie), they use passives, I do notice that they are consciously trying to avoid Sie, it is not always so though, many also try to use Sie to hear if they do it right (Teacher B)

Following the simulation, students had commented to the teachers that the exercise had been awkward for them, as teacher $D$ reported:

Yes, an unfamiliar situation, we (i.e., the students) did not really dare or we had no motivation to use Sie (Teacher D)

Some students also reported avoiding directly addressing the interlocutor when they had to use $\mathrm{V}$ :

It is somehow unsafe. You have the feeling of being on thin ice (...) when you have to address the teacher with Sie. (...) It is very unfamiliar and you try to find an alternative (...) (Student A)

This avoidance strategy is a kind of rejection, but the students did not resort to the Danish $\mathrm{T}$; instead, they avoided addressing the lecturer directly. They used passives like Ist diese Aufgabe schon besprochen worden? ("Has this assignment already been discussed?") instead of the addressee-oriented: Haben Sie diese Aufgabe schon besprochen? ("Have you already discussed this assignment?"). These strategies, although grammatically more challenging to use, may relieve them both of the burden of using $V$ and of the error of using $T$ in a German academic context. Interestingly, teacher A-a native German-reported on a similar situation at an oral exam: She intended to use $\mathrm{V}$, but the second examiner used $\mathrm{T}$. To avoid an odd situation where both $\mathrm{V}$ and $\mathrm{T}$ were used, she adopted the avoidance strategy, trying not to address the student directly.

I did not want there to be a huge clash between him saying $d u$ and me having a more mixed approach, I used neutral expressions [So you avoided using du?] Yes. If I had been alone with them I would have addressed them directly (Teacher A) 
We also found evidence that students coped with $\mathrm{V}$ by using the rationalization strategy outlined in Maertz et al. (2009), i.e., the adoption of a foreign behavior to achieve a specific goal. We noted above that the students were more inclined to accept $\mathrm{V}$ in the presence of a native German teacher, and the teachers endorsed this:

I think it has to do with your backgrounds. You are a Dane, "you will educate us to use Sie, that is outrageous," while NN is German, in that case it is the normal thing to do (Teacher C)

\section{Discussion and implications}

We set out to explore the perceptions of Danish students and teachers toward using the German $\mathrm{V}$ in a CLIL classroom in Denmark. We found that Danes-both students and teachers-reported awareness of the German conventions and their importance for intercultural competence. Yet in practice, both groups reported feeling awkward, to a greater or lesser extent, about using $\mathrm{V}$. Moreover, the teachers themselves admitted that they tended to avoid $\mathrm{V}$, and they reported (perhaps unsurprisingly) that the students did too. Reluctance to using $V$ was, however, reported to be mitigated by a genuine German context, understood as actually being in a German-speaking country and/or with a native speaker of German. We noted that $V$ was associated with negative connotations by the Danish teachers and students, but that they were nevertheless willing to cope with $V$ under specific circumstances. The students emphasized the need for a repeated, formal justification for the use of $\mathrm{V}$, if $\mathrm{V}$ was required in the classroom. In other words, it should not simply be accepted without cause.

Our data also suggest, in line with Maertz et al. (2009), that CCD arises when speaking with other Danes in a Danish context because $V$ conflicts strongly with egalitarianism, ${ }^{11}$ a core Danish cultural value to which our interviewees seemed very attached, which is reflected in teaching situations where the implicit cultural contract between teacher and students is that they are on an equal footing. The discomfort with $\mathrm{V}$ therefore results from different interpretations of the meaning behind signaling social or personal distance in Germany as opposed to Denmark. Cook (2014, p. 21) suggested that the social or personal distance between speaker and hearer signaled by German $V$ is associated with respect for the interlocutor as a human being. In a Danish context, overtly marking social distance appears to be interpreted as undermining the goal of desired equality and/or intimacy. In that regard, $\checkmark$ has the same pragmatic effect in German and Danish, but the effect is evaluated differently-in Denmark, more or less negatively; in Germany, more or less positively, as a sign of respect. So even though Danish students and teachers acknowledged that $\mathrm{V}$ created a serious and professional atmosphere, they still viewed it as undermining equality and producing social hierarchies and distance, and not as being cozy or comfortable (hyggeligt). This is consistent with Maertz et al.'s arguments (see also Yates, 2010; Bardovi-Harlig \& Dörnyei, 1998), outlined earlier, that CCD may interfere with learners' willingness or ability to produce a given behavior even while rationally grasping the benefits of doing so (cf. Norouzian \& Eslami, 2016).

The above-mentioned findings resonate with scholarship on Danish culture, which generally concurs that Danes hold dear the value of equality because it fosters mutual trust; and that this value, combined with a strong emphasis on independence and autonomous thinking, results in a culture where titles and other expressions of deference that mark status differences are regarded as superfluous, and with suspicion (Jenkins, 2011; Nørmark, 2013). These observations are substantiated by large-scale surveys of values, such as the World Values Survey (WVS, 2008), as well as surveys carried out by, e.g., Hofstede (2001) and

\footnotetext{
${ }^{11}$ See also Clyne et al. (2006, p. 291), who state that the emergence of Swedish du resonated with the egalitarian
} ideals of Sweden in the late 1960s. 
Schwartz (1992). All in all, we may surmise that Danes are likely to feel uncomfortable with overt manifestations of hierarchies, and that this is what we see reflected in our data.

Our study also suggests the need for three refinements to the CCD coping strategy of explicit host VABN rejection outlined in Maertz et al. (2009). First, rejection is not necessarily outright but can take the form of a partial concession to the foreign (here linguistic) behavior-namely avoiding $\mathrm{V}$ by circumventing direct address. Second, Maertz et al.'s model assumes that rejection is purposeful, yet our data suggest that many students were not even aware that they were using $\mathrm{T}$ instead of $\mathrm{V}$. Our findings are more in line with work on pragmatic transfer which addresses the influence-be it purposeful or unconscious-of languages other than L2 on the comprehension, production, and learning of L2 pragmatic norms (Kasper, 1992). If the teacher were to insist on using $\mathrm{V}$, however, then the students may reject it outright, since they would find this request-if left unexplained-unreasonable and/or alienating coming from a fellow Dane. This strongly suggests that in Danish CLIL classrooms, students relate to their teacher primarily as a fellow Dane rather than as a German language teacher, and that they seem to transfer their cultural expectations of how a Dane should behave to him or her. This is consistent with Hinkel's (2014) and Gardner's (2007) points, outlined earlier, that the cultural context influences the educational context, as well as with work showing how students can negotiate cultural identities in the classroom in ways that can undermine the teacher's learning goals (see, e.g., Auerbach, 1995). Using $V$ would then become uncomfortable or even unacceptable to them, as their comments in the class evaluations show. This dynamic, whereby students expect that teachers' cultural behaviors should be aligned with the native language context, may also be reflected in other national contexts and therefore constitutes a rich area for further research on CLIL teaching. Third, since VABNs have normally been thought of as intrinsic to individuals, CCD resulting from a foreign behavior should be fairly stable across situations (Maertz et al., 2009, p. 69); yet according to our data, the location (notably whether the exchange is taking place on the learner's "home soil"), the specific situation (e.g., a teaching situation), and the cultural backgrounds of the interlocutors all affect the degree of CCD experienced, ranging from slight discomfort to anxiety that can render a person speechless. We also noted a range of reported effects on performance, ranging from unconscious omission to avoidance to purposeful/explicit rejection.

Our study highlights the need, in CLIL classrooms, to explicitly raise students' awareness of how situation, location, and the interlocutor's cultural background may affect their attitudes toward adopting foreign pragmatic conventions as well as their willingness to endure any resulting discomfort, in particular when "at home." CLIL teachers should also be aware of how particular language features may be culturally "loaded" for students from specific L1 cultural backgrounds. For instance, German $\mathrm{V}$ may be less challenging for students whose mother tongue also features commonplace uses of $\mathrm{V}$ than for those whose mother tongue features $\mathrm{V}$ as a strongly, negatively marked word denoting social hierarchy. This is a promising area for future research. A further measure that teachers could take would be to explain the different pragmatic meanings inherent in the Danish $\mathrm{T}$ compared to the German V: i.e., that $\mathrm{V}$ in German is not marked in the same way as it would be in Danish-except when violated, which usually only occurs in clearly hierarchical relationships or in service encounters where it can be regarded as belittling to use $d u$.

Our findings also invite us to rethink how consistently and rigidly forms of address are taught in CLIL classrooms, notably in light of research showing the importance of expectations of the educational system in shaping attitudes to language learning (Gardner, 2007). First, our data clearly show that in real-world classroom contexts, students receive very "mixed messages" (Grenfell \& Harris, 1999, p. 41) from their teachers, some of whom insist on V in all situations, while others are more flexible or skip it altogether in favor of T. Some teachers even simply forget to use V. A more consistent approach, agreed upon by teachers of the same students, might be one way to avoid confusion and a "default" response of pragmatic transfer. It is worrying that some students in our study clearly experienced varying degrees of anxiety in 
connection with $\mathrm{V}$, something that is clearly not conducive to learning. The foreign language classroom should offer "a safe place within which learners can try out new forms and patterns of communication in an accepting environment... [and] experiment with unfamiliar forms of address" (Bardovi-Harlig \& Mahan-Taylor, 2003, p. 39). One possible explanation for the students' anxiety is that teachers may unwittingly be overemphasizing the strictness of the boundaries between $V$ and $T$ in modern German usage, as well as the negative reactions that may occur if students were to misuse these address forms in a German context. In that regard, Clyne et al. (2006) noted that key studies on the functions of address forms in different cultures "are no longer up-to-date and their empirical bases have often been inadequate." (2006, p. 287). Specifically with regard to German, the authors reported the coexistence of two different address conventions: one (V) representing a more traditional, conservative convention, significantly regional; and the other $(T)$ representing "egalitarian, socially progressive attitudes" (2006, p. 292). However, they also noted that these two should be seen as "prototypes," and that in practice, "the address patterns of German are marked by fluctuations and insecurity" (2006, pp. 292-293). Their data revealed numerous episodes of "fuzziness" and uncertainty over which situations were appropriate for using $V$ or $T$ even among native German speakers. The data also showed that address practices, particularly in private networks, were open to negotiation, and that factors such as age/generation, perceived affinities between people, political/ideological affiliation, and social context played a role in this, as well as more general changes over time - notably since the 1960 s student movement - towards a "decline in the strong social meaning of a T/V-distinction and the subsequent increase in the role of negotiation" (2006, p. 296). While one should not ignore the fact that pragmatic errors by foreign speakers are less well tolerated by native speakers than, e.g., pronunciation or syntax errors, and that teachers should play a key role in alerting students to this (Vandermeeren, 2003; Wolfson, 1983/2013, p. 62), we suggest that CLIL teachers should avoid overemphasizing this to the point of instilling anxiety in their students about committing errors, and possibly also unwittingly reinforcing cultural stereotypes, such as those documented in some cross-cultural research that Germans are "serious" and "unfriendly" (Sosnizkij, 2003). After all, "the goal of instruction in pragmatics is not to insist on conformity to a particular target-language norm, but rather to help learners become familiar with the range of pragmatic devices and practices in the target language" (BardoviHarlig \& Mahan-Taylor, 2003, p. 38). Teachers could, instead, provide examples of changes in use of $\mathrm{V}$ over time, as well as regional and situational variations (see also Ishihara \& Cohen, 2014; Barron, 2006), and alert students to the idea that pragmatic conventions, just like culture itself, can be seen more in terms of diversity, tendencies, and ranges than "absolute, prescriptive rules" (Ishihara \& Cohen, 2014, p. 13, see also Dervin \& Liddicoat, 2013).

Finally, CCD and its dependence on situational factors have consequences for CLIL approaches and for intercultural training in general. CLIL is generally seen as a suitable didactic approach for teaching intercultural competences given that language is so closely intertwined with culture (Sudhoff, 2010); moreover, CLIL is normally thought to foster positive attitudes toward the foreign language and its native speakers (Pérez-Cañado, 2012, p. 317), rather than negative ones. It is therefore often assumed to be an obvious didactic strategy for strengthening intercultural awareness. At the same time, CLIL usually takes place "at home." Yet, as the present investigation shows, discomfort with, or reluctance toward, adopting foreign cultural conventions may be at its strongest "at home" -especially if the teacher is not a native speaker of the language-something which may work against the practice of target language conventions in CLIL teaching situations. Also, although research indicates that "egalitarian traditions and norms are potent forces promoting racial equality" (Dovidio \& Gaertner, 2000, p. 315), we argue that in this case, strong attachment to egalitarian values in Danish culture may be an obstacle to cultural adaptation and possibly also more broadly a barrier to accepting foreign conventions viewed as clashing with these values, especially "at home." Indeed, the tendency we identified for situation to affect willingness to adopt foreign pragmatic conventions is also reflected at a broader level in scholarship on attitudes toward 
foreigners and foreignness in Denmark. Hervik (2004, p. 250), for instance, noted a prevalent "hosts-guests" Danish cultural schema that typically manifested as the conviction that foreigners should conform to local conventions, and not vice versa. However, like us, Hervik observed that location modifies this schema, so that being on one's own territory seems to mitigate any obligation to accept or adapt to difference. The implications of this for CLIL teaching constitute a rich area for future research.

\section{Conclusion}

In a context of increasingly globalized workplaces and migration, students must not only learn to adapt to foreign cultural conventions when abroad but also, increasingly, at home. However, as we show here, this is easier said than done. It involves not only increased openness to otherness but also the ability to become aware of, and suspend, normative and emotive attachment to one's own cultural worldview (Guilherme, 2002; Nagata, 2004; Stier, 2006) and, as we have shown, the willingness to endure any resulting discomfort and to adapt one's behavior accordingly.

Specifically, we analyzed the discomfort experienced by Danish students and teachers when using the German polite form of address, Sie (V), in CLIL German classrooms. We showed how Danes report that $V$ causes them to experience a conflict with their egalitarian values, which are also reflected in the classroom, resulting in cognitive dissonance. The discomfort arises most strongly when Danes encounter $\mathrm{V}$ on their home territory, but also to a lesser extent when they are in a German-speaking country. However, they reported that their willingness to endure this discomfort, and to overcome it by actually using $\mathrm{V}$-and indeed their very awareness that they were using $\mathrm{V}$ at all-was greatly reduced when at home compared to when abroad or when faced with a Danish native interlocutor as opposed to a German one. CLIL courses by definition take place "at home" and are often taught by L2 nonnative speaker teachers, so we should expect that students may face particular difficulties in integrating language and culture under circumstances in which they are the least disposed toward adopting "foreign" cultural behaviors.

Our findings suggest the need for attention, in intercultural education, to the role played by situation/location and the cultural background of the interlocutor in adaptation to foreign pragmatic conventions. These points go to the heart of the highly sensitive question of who should adapt-the "host" or the "guest" (Hervik, 2004; see also Mouritsen \& Olsen, 2013)in situations in which people from different cultures coexist in what is conceived of as the home territory of one of the groups. This question could not be more pertinent in Scandinavia today, where large migrant flows have placed the region at the center of political, social, and cultural debates, and where business encounters also increasingly require adaptation to foreign cultural conventions at home. As CLIL teachers, working to support students' ability and willingness to use foreign cultural conventions is one arena in which it is possible to challenge any incipient tendencies to assume that cultural adaptation is only required when abroad. 


\section{References}

Auerbach, E. R. (1995). The politics of the ESL classroom: Issues of power in pedagogical choices. In J. Tollefson (Ed.), Power and inequality in language education (p.9-33). Cambridge: Cambridge University Press.

Bachman, L. F., \& Palmer, A. S. (1996). Language testing in practice: Designing and developing useful language tests (Vol. 1). Oxford: Oxford University Press. https://doi.org/10.1177/026553229601300201

Bardovi-Harlig, K., \& Dörnyei, Z. (1998). Do language learners recognize pragmatic violations? Pragmatic versus grammatical awareness in instructed $L 2$ learning. Tesol Quarterly, 32(2), 233-259. https://doi.org/10.2307/3587583

Bardovi-Harlig, K., \& Mahan-Taylor, R. (2003). Teaching pragmatics. Washington DC: US Department of State Office of English Language Programs.

Barron, A. (2006). Learning to say 'you' in German: The acquisition of sociolinguistic competence in a study abroad context. In M. A. DuFon \& E. E. Churchill (Eds.), Language learners in study abroad contexts (pp. 59-88). Clevedon: Multilingual matters. https://doi.org/10.21832/9781853598531-007

Besch, W. (1998). Duzen, siezen, titulieren. Zur anrede im Deutschen heute und gestern [To be on-first-name-terms, to address formally, to entitle someone. On addressing in German today and yesterday]. Göttingen: Vandenhoeck \& Ruprecht.

Breen, M. P., \& Littlejohn, A. (2000). The significance of negotiation. In M. P. Breen \& A. Littlejohn (Eds.), Classroom decision making: Negotiation and process syllabuses in practice (pp. 5-39). Cambridge: Cambridge University Press.

Brown, R. \& Gilman, A. (1960). The pronouns of power and solidarity. In T. A. Sebeok (Ed.), Style in Language (pp. 253-76). Cambridge, MA: MIT Press.

Byram, M. (1997). Teaching and assessing intercultural communicative competence. Clevedon: Multilingual Matters.

Børsen (2015). Tal tysk og lær at sige De. March 6, 2015. Retrieved from http://borsen.dk/nyheder/avisen/artikel/11/106701/artikel.html

Clyne, M., Kretzenbacher, H. L., Norrby, C., \& Schüpbach, D. (2006). Perceptions of variation and change in German and Swedish address. Journal of Sociolinguistics, 10(3), 287-319. https://doi.org/10.1111/j.1360-6441.2006.00329.x

Cook, M. (2014). Beyond T and V - Theoretical reflections on the analysis of forms of address. American Journal of Linguistics, 3(1), 17-26.

Coyle, D. (2007). Content and language integrated learning: Towards a connected research agenda for CLIL pedagogies. International Journal of Bilingual Education and Bilingualism, 10(5), 543-562. https://doi.org/10.2167/beb459.0

Culpeper, J., Schauer, G., Marti, L., Mei, M., \& Nevala, M. (2014). Impoliteness and emotions in a cross-cultural perspective. SPELL: Swiss Papers in English Language and Literature, 30, 67-88.

Dalton-Puffer, C. (2007). Discourse in content and language integrated learning (CLIL) classrooms (Vol. 20). Amsterdam/Philadelphia: John Benjamins Publishing. https://doi.org/10.1075/IIlt.20

"Den moderne lærer er en autoritet, der ikke er autoritær," (2014, July 29). Information. Retrieved from https://www.information.dk/kultur/2014/07/moderne-laerer-autoritetautoritaer

Dervin, F., \& Liddicoat, A. J. (Eds.). (2013). Linguistics for intercultural education (Language Learning \& Language Teaching, vol. 33). Amsterdam/Philadelphia: John Benjamins Publishing. 
Dewaele, J.-M. (2011). Reflections on the emotional and psychological aspects of foreign language learning and use. Anglistik: International Journal of English Studies, 22(1), 23-42.

Dovidio, J. F., \& Gaertner, S. L. (2000). Aversive racism and selection decisions: 1989 and 1999. Psychological Science, 11(4), 315-319.

https://doi.org/10.1111/1467-9280.00262

Faerch, C. \& Kasper. G. (1989). Internal and external modification in interlanguage request realization. In S. Blum-Kulka, J. House, \& G. Kasper (Eds.), Cross-cultural pragmatics: Requests and apologies (pp. 221-248), Norwood, NJ: Ablex Publishing Corporation.

Fasold, R. (1984). The sociolinguistics of society. Oxford, UK and Cambridge, USA: Blackwell.

Fouché, C. B., \& Chubb, L. A. (2016). Action researchers encountering ethical review: A literature synthesis on challenges and strategies. Educational Action Research, 1-12.

Gardner, R. C. (2007). Motivation and second language acquisition. Porta Linguarum, 8, 920.

Gardner-Chloros, P. (2009). Code-switching. Cambridge, UK, New York: Cambridge University Press. https://doi.org/10.1017/CB09780511609787

Garrett, P. (2010). Attitudes to Language. Cambridge: Cambridge University Press. https://doi.org/10.1017/CBO9780511844713

Giroux, H. A. (2001). Theory and resistance in education: Towards a pedagogy for the opposition. Westport, Connecticut: Bergin \& Garvey.

Grenfell, M., \& Harris, V. (1999). Modern languages and learning strategies: In theory and practice. London: Routledge.

Guilherme, M. (2002). Critical citizens for an intercultural world. Clevedon: Multilingual Matters. https://doi.org/10.21832/9781853596117

Haas, C. (2008). Citizenship education in Denmark: Reinventing the nation and/or conducting multiculturalism. London Review of Education, 6(1), 59-69. https://doi.org/10.1080/14748460801889902

Hammersley, M., \& Traianou, A. (2012). Ethics and educational research. British Educational Research Association. Retrieved from:

http://www.learnersfirst.net/private/wp-content/uploads/Ethics-and-EducationalResearch.pdf.

Haugh, M. (2010). Intercultural (im)politeness and the micro-macro issue. In A. Trosborg (Ed.), Pragmatics across languages and cultures (Vol. 7) (pp. 139-167). Berlin/New York: De Gruyter Mouton.

Hervik, P. (2004). The Danish cultural world of unbridgeable differences. Ethnos, 69(2), 247-267. https://doi.org/10.1080/0014184042000212885

Hinkel, E. (2014). Culture and pragmatics in language teaching and learning. In: M. CelceMurcia, D. Brinton, \& M. Snow (Eds.), Teaching English as a Second or Foreign Language, Boston : National Geographic Learning : Heinle Cengage Learning, 394-408.

Hofstede, G. (2001). Culture's recent consequences: Using dimension scores in theory and research. International Journal of Cross Cultural Management, 1(1), 11-30. https://doi.org/10.1177/147059580111002

Hornberger, N. H., \& Link, H. (2012). Translanguaging and transnational literacies in multilingual classrooms: A biliteracy lens. International Journal of Bilingual Education and Bilingualism, 15(3), 261-278. https://doi.org/10.1080/13670050.2012.658016

Ishihara, N., \& Cohen, A. D. (2014). Teaching and learning pragmatics: Where language and culture meet. London, New York: Routledge. https://doi.org/10.4324/9781315833842

Jenkins, R. (2011). Being Danish: Paradoxes of identity in everyday life. Copenhagen: Museum Tusculanum. 
Jensen, T. (2006). The cartoon crisis revisited: A Danish perspective. Elcano Newsletter, 26, Real Instituto Elcano.

Jeon, E.H., \& Kaya, T. (2006). Effects of L2 instruction on interlanguage pragmatic development: A meta-analysis. In. J.M. Norris \& L. Ortega (Eds). Synthesizing research on language learning and teaching (pp. 165-211). Amsterdam: John Benjamins. https://doi.org/10.1075/lllt.13.10jeo

Kasper, G. (1992). Pragmatic transfer. Second Language Research 8(3), 203-231.

Kecskes, I. (2014). Intercultural pragmatics. Oxford: Oxford University Press. https://doi.org/10.1016/j.pragma.2013.09.004

Kinginger, C., \& Belz, J. A. (2005). Socio-cultural perspectives on pragmatic development in foreign language learning: Microgenetic case studies from telecollaboration and stay abroad. Intercultural Pragmatics, 2(4), 369-421. https://doi.org/10.1515/iprg.2005.2.4.369

Kingsley, P. (2012). How to be Danish: From Lego to Lund: A short introduction to the State of Denmark. London: Short.

Knudsen, A. (2002). Her gar det godt, send flere penge. Copenhagen: Gyldendal.

Lemke, J. L. (1990). Talking science: Language, learning and values. Norwood NJ: Ablex Publishing Corporation.

Liao, X. (1996). Developing Awareness of Cross-cultural Communication. Report from US Department of Education. Retrieved from https://files.eric.ed.gov/fulltext/ED399820.pdf

Liddicoat, A. J. (2006). Learning the culture of interpersonal relationships: Students' understandings of personal address forms in French. Intercultural Pragmatics, 3(1), 55-80. https://doi.org/10.1515/IP.2006.003

Luo, X., \& Gao, J. (2011). On pragmatic failures in second language learning. Theory and Practice in Language Studies, 1(3), 283-286. https://doi.org/10.4304/tpls.1.3.283-286

Maertz, C. P., Hassan, A., \& Magnusson, P. (2009). When learning is not enough: A process model of expatriate adjustment as cultural cognitive dissonance reduction. Organizational Behavior and Human Decision Processes, 108, 66-78. https://doi.org/10.1016/j.obhdp.2008.05.003

Mehisto, P. (2008). CLIL counterweights: Recognising and decreasing disjuncture in CLIL. International CLIL Research Journal, 1(1), 93-119.

Molinsky, A. (2007). Cross-cultural code-switching: The psychological challenges of adapting behavior in foreign cultural interactions. Academy of Management Review, $32(2), 622-640$. https://doi.org/10.5465/amr.2007.24351878

Mouritsen, P., \& Olsen, T. V. (2013). Denmark between liberalism and nationalism. Ethnic and Racial Studies, 36(4), 691-710. https://doi.org/10.1080/01419870.2011.598233

Nagata, A. L. (2004). Promoting self-reflexivity in intercultural education. Journal of Intercultural Communication, 8, 139-67.

Ng, K. Y., Van Dyne, L., \& Ang, S. (2012). Cultural intelligence: A review, reflections, and recommendations for future research. In A. M. Ryan, F. T. L. Leong, \& F. L. Oswald (Eds.), Conducting multinational research: Applying organisational psychology in the work place (pp. 29-58). Washington, DC: American Psychological Association. https://doi.org/10.1037/13743-002

Norouzian, R., \& Eslami, Z. (2016). Critical perspectives on interlanguage pragmatic development: An agenda for research. Issues in Applied Linguistics, 20(1), 25-50.

Nørmark, D. (2013). Cultural intelligence for stone-aged brains: How to work with Danes and beyond. Copenhagen: Gyldendal Business. 
Olshtain, E. \& Cohen, A. D. (1989). Speech act behaviour across languages. In H. W. Dechert \& M. Raupach (Eds.), Transfer in production (pp. 53-67), Norwood, NJ: Ablex.

Ørsnes, B. (2016). Forms of address as intercultural code-switching: The case of German and Danish in higher education. In E. Hallsteinsdóttir \& J. Kilian (Eds.), \{deutsch\} und \{dänisch\} im Stereotyp: Stereotypenwelten und ihre sprachlich-kulturellen Konstituierungsformen, Linguistik online, vol. 79(5) (pp. 179-198).

Pérez-Cañado, M. L. (2012). CLIL research in Europe: Past, present, and future. International Journal of Bilingual Education and Bilingualism, 15(3), 315-341. https://doi.org/10.1080/13670050.2011.630064

Rokeach, M. (2008). Understanding human values. New York: Simon and Schuster.

Schmidt, R. (1993). Consciousness, learning and interlanguage pragmatics. In G. Kasper \& S. Blum-Kulka (Eds.), Interlanguage pragmatics (pp. 21-42). Oxford: Oxford University Press.

Schmidt, R. (2001). Attention. In P. Robinson (Ed.), Cognition and second language instruction (pp. 3-32). Cambridge: Cambridge University Press. https://doi.org/10.1017/CB09781139524780.003

Schwartz, S. H. (1992). Universals in the content and structure of values: Theoretical advances and empirical tests in 20 countries. In Advances in Experimental Social Psychology 25, 1-65. https://doi.org/10.1016/S0065-2601(08)60281-6

Sharwood-Smith, M. (1991). Speaking to many minds: On the relevance of different kinds of language information for the L2 learner. Second Language Research, 7(2), 118-132.

Siegal, M. (1996). The role of learner subjectivity in second language sociolinguistic competency: Western women learning Japanese. Applied Linguistics, 17(3), 356-382. https://doi.org/10.1093/applin/17.3.356

Sosnizkij, B. (2003). Stereotypes in cross cultural communication regarding Germans. Seminar paper, University of Lincoln. Retrieved from http://www.grin.com/en/e-book/26199/stereotypes-in-cross-cultural-communicationragarding-germans.

Spencer-Oatey, H. (2010). Intercultural competence and pragmatics research: Examining the interface through studies of intercultural business discourse. In A. Trosborg (Ed.). Pragmatics across languages and cultures (Vol. 7) (pp. 189-216). Berlin, New York: de Gruyter Mouton.

Stier, J. (2006). Internationalisation, intercultural communication and intercultural competence. Journal of Intercultural Communication, 11, 1-12.

Den Store Danske Encyklopædi. 1997. Vol. 9. Copenhagen: Gyldendal.

Sudhoff, J. (2010). CLIL and intercultural communicative competence: Foundations and approaches towards a fusion. International CLIL Research Journal, 1(3), 30-37.

Swain, M. (1995). Three functions of output in second language learning. In G. Cook \& B. Seidlhofer (Eds.), Principle \& Practice in Applied Linguistics (pp. 125-144). Oxford: Oxford University Press.

Thomas, D. C., Elron, E., Stahl, G., Ekelund, B. Z., Ravlin, E. C., Cerdin, J. L., \& Maznevski, M. (2008). Cultural intelligence domain and assessment. International Journal of Cross Cultural Management, 8(2), 123-143. https://doi.org/10.1177/1470595808091787

Trosborg, A. (Ed.). (2010). Pragmatics across languages and cultures (Vol. 7). Berlin, New York: de Gruyter Mouton. https://doi.org/10.1515/9783110214444

Vandermeeren, S. (2003). German language needs in Danish companies. HERMES-Journal of Language and Communication in Business, 31, 13-29. 
Wierzbicka, A. (2010). Cultural scripts and international communication. In A. Trosborg (Ed.), Pragmatics across languages and cultures (Vol. 7) (pp. 43-79). Berlin, New York: de Gruyter Mouton.

Wolfson, N. (1983/2013). Rules of speaking. In J. C. Richards \& R. W. Schmidt (Eds.), Language and communication (pp. 61-88). London/New York: Routledge.

World Values Survey. (2008). Cultural map - WVS Wave 5. Retrieved from http://www.worldvaluessurvey.org/WVSContents.jsp

Yates, L. (2010). Pragmatic challenges for second language learners. In A. Trosborg (Ed.), Pragmatics across languages and cultures (Vol. 7) (pp. 287-308). Berlin, New York: de Gruyter Mouton.

Žegarac, V., \& Pennington, M. C. (2000). Pragmatic transfer in intercultural communication. In H. Spencer-Oatey (Ed.), Cultural Speaking: Managing Rapport Through Talk Across Cultures (pp. 165-190). London/New York: Continuum.

Zeit Online. (2015). Master in Deutschland: Bei uns geht das anders. August 2, 2015. Retrieved from https://www.zeit.de/campus/2015/s2/master-deutschland-russlanddaenemark-rumaenien-unterschiede 